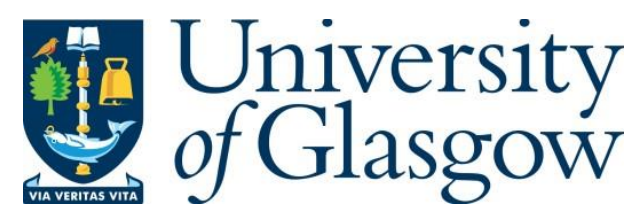

O'Neill, J. (2021) Lessons from the vaginal mesh scandal: enhancing the patient-centric approach to informed consent for medical device implantation. International Journal of Technology Assessment in Health Care, 37(1), e53.

There may be differences between this version and the published version. You are advised to consult the publisher's version if you wish to cite from it.

http://eprints.gla.ac.uk/238565/

Deposited on: 27 April 2021

Enlighten - Research publications by members of the University of Glasgow http://eprints.gla.ac.uk 


\title{
Lessons from the Vaginal Mesh Scandal; Enhancing the Patient-Centric Approach to \\ Informed Consent for Medical Device Implantation.
}

\author{
AUTHORS AND INSTITUTIONS \\ Jennifer O’Neill, DipHE, BSc(Hons), LLB(Hons), FHEA \\ Lecturer, University of Glasgow, Glasgow, G12 8QQ \\ Email: Jennifer.oneill@glasgow.ac.uk
}

\begin{abstract}
The vaginal mesh scandal, in which thousands of women were irreversibly maimed by polypropylene mesh, revealed multi-level failures in medical device regulation and implantation, demonstrating that patient-centric care has not yet fully transcended from policy into practice. In law, informed consent is considered by a two-stage test; reasonable treatment and patient information disclosure. The standard of reasonable treatment is determined according to the what is deemed acceptable in accordance with a body of medical opinion. However, such bodies of medical opinion were vulnerable to external influence from device manufactures. Vaginal mesh manufacturers were found to have had financial links to research, royal colleges and influential clinicians which then influenced the basis of the evidence-based practice which often guides such bodies of medical opinion. According to the Independent Medicines and Medical Device Safety Report, patients' mesh complications were also frequently under-reported and patient-based evidence of harm disregarded. Patients were also not sufficiently informed of the material risks or reasonable alternatives to mesh, which is required of the second stage of informed consent pertaining to information disclosure. This paper makes the following recommendations; that conflict of interest disclosure be mandated, that greater value be afforded to patient-based evidence to improve evaluation of treatments, and that information disclosure for informed consent should relate to the risks, benefits and alternatives to the surgical procedure and medical device. This will ensure that patients can evaluate whether surgeons are offering unbiased treatment options, and are also informed of the potential long-term risks associated with device implantation.
\end{abstract}

\section{KEYWORDS:}

Informed Consent, Vaginal Mesh, Information Disclosure, Evidence-Based Practice, Montgomery 
Competing Interests: None declared.

Contributorship Statement: I am the sole author of this manuscript.

Funding statement: This research received no specific grant from any funding agency, commercial or not-for-profit sectors.

\section{Introduction}

In 2012, the United Kingdom Department of Health published the new policy document No Decision About Me, Without Me which acknowledged a new era of patient-centric care [1]. The aim was to promote such patient-centric care and improve patient involvement in healthcare through shared decision-making [1]. It was anticipated that this would improve care strategies [1]. Such intent was echoed by the General Medical Council's (GMC) publication Good Medical Practice which directed doctors to work with patients to attain better clinical outcomes [2]. However recent high-profile medical device scandals, in which patients were harmed by implantable devices, demonstrate that patient-centric care has not yet fully transcended into practice [3]. The Independent Medicines and Medical Device Safety Review (IMMDR) and its subsequent Report "First Do No Harm" revealed that surgeons frequently failed to listen to patients' life-altering experiences of mesh implantation and often underreported adverse effects [4][5]. Affected patients also claimed to have been misled or misinformed during the informed consent process [4][5]. This suggests that there are two main barriers to patient-centric care and informed consent in device implantation surgery. Firstly, that patient-based evidence of treatment outcomes is often over-looked despite being a potentially valuable resource for improving healthcare outcomes. Secondly, that standards of information disclosure for informed consent as per Montgomery $v$ Lanarkshire case of March 2015 [6] have yet to fully transcend into practice. The landmark medical consent case changed 
legal standards of consent to treatment by recognising that patients should be told what they want to know about a treatment rather than what a doctor thinks they should know. It created a new legal duty upon doctors to fully inform patients of the material risks of treatment, benefits and any viable alternatives when gaining consent for medical treatment. It is proposed that disclosure of material risks should not be restricted to risks directly associated with the surgical procedure but should also reference long-term risks associated with device implantation, such as erosion or toxicity.

\section{Implantable Devices: Lessons from the Vaginal Mesh Scandal}

A medical device may be defined as "an instrument, apparatus, appliance, material or other article...which is intended by the manufacturer to be used for human beings for the purpose of diagnosis, prevention, monitoring, treatment or alleviation of disease..." [7]. Pharmaceutical drugs and implantable medical devices share a commonality in that they are designed to work within the human body. In the European Union (EU), pharmaceuticals undergo rigorous clinical trials, stringent regulation and strict post-marketing surveillance. By comparison, medical devices are often insufficiently tested and may be awarded CE certification by Notified Bodies with insufficient medical knowledge [8]. Despite the intention that it address the shortcomings of current EU Medical Device Directives, Bowers suggests that the anticipated EU Regulation 2017/745 will merely allow manufacturers to “...specify and justify the level of clinical evidence necessary to demonstrate ... general safety.."[9][10]. This requirement to submit minimal information will likely maintain the status-quo of self regulation amongst device manufacturers and allow unproven and potentially unsafe devices to be used inside patients [3]. Pharmaceutical manufacturers must include clinical trial evidence, including risks, on the Summary of Product Characteristics (SmPC). Yet there is no specification that device manufacturers need disclose all risks in corresponding Information for Use (IFU) leaflets. It 
is also not uncommon for manufacturers to forego clinical trials altogether if an equivalent device is already on the market [3]. This was the case for toxic metal-on-metal hip implants and mutilating transvaginal mesh made from polypropylene[3]. In the 1950s polypropylene was proclaimed to be the first man-made plastic deemed suitable for implantable medical devices [11]. Experts have since testified that it is, in fact, an unstable material that never should have been used inside the human body[3]. Initially used to treat abdominal herniae [4], Johnson \& Johnson's subsidiary company Ethicon sponsored the research, development and safety studies into the use of polypropylene mesh (also known as transvaginal tape) as a treatment for stress urinary incontinence in 1997 [12]. Having sponsored the research, Ethicon heavily influenced researchers to report favourable findings [12] Those findings, which were likely subject to bias, formed the basis of the evidence-based practice which promoted mesh as a treatment for stress urinary incontinence [12]. Polypropylene mesh was also subsequently indicated for the treatment of pelvic organ prolapse (POP) [4][12]. Ethicon played an instrumental role in the promotion of mesh for urogynaecological indications[4], yet in 2019 the company was found guilty of withholding knowledge that their mesh could leave women in chronic pain [13]. The $\$ 41$ million Penn State lawsuit heard that the company had considered suppressing studies showing unfavourable data or those highlighting the potential for chronic pelvic pain and increased morbidity[13]. Further complications included urinary and intestinal dysfunction, dyspareunia and mesh-induced-injury of sexual partners [4][14]. Evidence showed that Ethicon also extensively marketed mesh at conferences and provided surgeons and Royal Colleges with financial incentives [4] [15]. Patient testimony pertaining to the harm they had suffered was often disregarded by the National Health Service (NHS) surgeons whose practice was based upon literature which favoured the intervention [4]. In some cases, women were even referred for psychiatric treatment instead of receiving an 
acknowledgement of their symptoms [4]. This is indicative of how a body of medical opinion may be unduly influenced by industry, conflict of interest or unreliable scientific evidence.

\section{CLINICAL JUDGEMENT}

\section{Conflict of Interest within a Body of Medical Opinion}

Good Medical Practice advises doctors to provide efficacious treatments according to existing evidence [2]. This guidance upholds principles of evidence-based practice which are intended to mitigate paternalism by ensuring that treatment options are not based upon outdated or unproven surgical preference but are instead proven to be safe and efficacious [16]. Evidencebased practice may be defined as the "conscientious, explicit and judicious use of current best evidence to inform decisions about the care of individual patients" [17]. In practice, the credibility of evidence is evaluated according to source, with quantifiable research considered more credible than other forms of evidence [17]. However, as will be addressed later, such a pecking-order of evidence often fails to recognise the value of patient-based evidence, such as treatment evaluation, patient experience or opinion[17]. As a result, evidence-based practice is a predominant factor in the treatment patients receive.

Under UK law, informed consent is a two-staged test [18]. The first stage test recognises that surgeons should exercise professional judgement in evaluating potential treatment options [19] and the second stage applies the Montgomery test to address the subsequent information which should be disclosed to patients in seeking their consent [7].

The first test of professional judgement is determined according to the Bolam Test which states that the standard of care should be in "..accordance with a practice accepted as proper by a 
responsible body of medical men skilled in that particular art.."[19]. Surgeons are therefore under a legal duty to propose treatments which are accepted as proper by a responsible body of similarly qualified surgeons. Nair J cautioned that this “ .... does not mean that a medical man can obstinately and pig-headedly carry on with some old technique if it has been proved to be contrary to what is really substantially the whole of informed medical opinion" [19]. Such a caveat recognises the whilst differences in medical opinion exist, there is an expectation that surgeons should keep up-to-date through evidence based practice. Since it is not possible to read every relevant published article, clinical guidelines can provide surgeons with valuable overview of standardised best practice [20]. Notably, the courts may also look to retain some judicial authority over the degree of professional self-regulation afforded by Bolam, by considering whether a practice is responsible, reasonable and logical so as to give greater consideration to external opinion [19] [20]. Yet the application of this is rare, and reliance upon the paternalistic Bolam Test and evidence-based practice continues [19] [21]. Caution must be applied when assessing care according to standards of professional judgement, as conflict of interest or external influence could create confirmation bias. Conflict of interest may be defined as ".... set of circumstances that creates a risk that professional judgement or actions regarding a primary interest will be unduly influenced by a secondary interest"[22]. The Evidence from the IMMDR strongly suggests that professional medical judgement relating to vaginal mesh may have been clouded by financial ties to industry and biased studies [12][15]. On this basis, greater priority needs to be given to the interests of patients and their experiences.

Gornall 2018 describes how influential clinicians involved in drafting mesh guidelines may have been subject to conflict of interest in this way, having received industry funding, sponsorship and incentives which could have then prejudiced their recommendations [15]. 
Similarly, Hurwitz 2004 argues that a high percentage of guidelines follow poor quality information and should not influence legal standards [16]. The IMMDR also reported that over the last ten years industry-sponsored studies with conflict of interests dominated the literature creating a false narrative of vaginal mesh efficacy[4]. Ethicon was just one of many mesh manufacturers found to have sponsored the influential Royal Colleges and conferences which are traditionally forums of research dissemination [15]. Such widespread industry influence can fuel bias and skew judgement of which patients are often unaware. To this end, Hampton warns that "guidelines are evidence filtered through opinion" [23]. It must be recognised therefore, that external influence may lead to inappropriate treatments being considered appropriate by a body of medical opinion [19].

\section{Patient-Based Evidence as a Valuable Component of Evidence-Based Practice}

A key argument in the UK class action case in 2018 of AH verses various Health Boards and Manufacturers, was that surgeons had not been aware of the risks associated with mesh [4][24]. However, patient testimony to the IMMDR suggests that complications had largely been ignored [4] and so the use of mesh continued in subsequent patients. Whilst patient-based evidence is increasingly recognised by the National Iinstitute for Clinical Excellence (NICE) [25] and some select areas of practice [26] it has yet to be fully embraced in surgical practice. Accordingly there are only three sources of treatment information available to surgeons; information from the manufacturer, their "skill and expertise as a reasonably competent doctor" and their obligation to "keep abreast of the developments in the field of medicine in which he practices by, for example, reading articles relating to treatments"[24]. Surgeons have a duty to keep up to date, attend meetings and read the literature to keep abreast of current developments [27]. Yet, as aforementioned, such information sources may be subject to bias or conflict of interest. A 2015 Cochrane Review identified a high potential for bias in mesh 
literature [28]. Arguably, such biased literature could have eclipsed studies highlighting the risks of mesh. Safety concerns were voiced as early as as 2007 with reports of erosion and pelvic organ damage yet mesh continued to be used surgically in England until 2017 [4][14]. Some five years earlier in 2012, the United States regulator - the Food and Drug Administration (FDA) - had raised concerns over the lack of mesh efficacy weighed against significantly increased complications rates compared to non-mesh alternatives [29]. Such complications included chronic pelvic and vaginal pain, vaginal constriction and associated dyspareunia which could have severe impact upon quality of life [14]. Greater emphasis on conflict of interest could ensure a more balanced playing field for unbiased literature, however the scandal also illustrates the need to recognise the value of patient-based evidence as integral in improving healthcare outcomes.

New European Regulation 2017/745 aims to ensure patients are heard, and protected, by creating a device registry to record adverse events [9]. This gives recognition to patient experience as a form of evidence which is often undervalued in evidence-based practice [17]. In fact, the IMMDR heard that valuable patient evidence of harm from mesh was often disregarded by surgeons in favour of the literature [17]. Had greater credibility been afforded to patient testimony, arguably, change could have come sooner. Wider incorporation of patient-based evidence could not only help mitigate bias but may also help to shape professional judgement through the adoption of a truly patient-centric approach to treatment. In adopting such an approach, patients can potentially inform doctors of their treatment experiences to reflect a model of mutual respect.

Samanta et al 2006 suggest that the increasing use of guidelines in litigation could mark a departure from the professional opinion standard of Bolam towards greater recognition of 
external sources of evidence, such as that from patient experience [19] [20]. Patient-based evidence, which has been shown to correlate with improved healthcare outcomes, could also be incorporated into the evidence-based practice framework to offer greater appreciation of what constitutes effective care [30]. Browne et al 2010 found patient-based evidence can help to expose problems so that practice can be improved [31]. A systematic review conducted in 2012 urged clinicians to recognise patient experience rather than to dismiss it as too subjective or as being non-scientific and without credence [30]. Patient-based evidence is also increasingly used by the NICE when there is a lack of scientific literature [25]. Arguably, incorporation of patient-based evidence within evidence-based practice could safeguard against conflicts of interests by alerting practitioners to poor patient experience, as was the case with vaginal mesh. One survey found that $71 \%$ of women in a mesh support group required long term analgesia and nearly half had considered suicide as a direct result of mesh surgery [4]. If such evidence had been incorporated into evidence-based practice perhaps other women need not have suffered in the same way. Patient-based evidence may also help rebuild trust. If other patients' experiences are referred to, at least in part, during the informed consent process, patients may feel better equipped to make treatment decisions.

\section{PATIENT INFORMATION DISCLOSURE}

\section{Information Disclosure for Implantable Devices}

Campell et al 2018 describe informed consent as "perhaps the most important ethical issue associated with the use of vaginal mesh in prolapse surgery" [32]. In law, the second stage of informed consent is that of information disclosure. According to the Supreme Court ruling in Montgomery, the surgeon is "under a duty to take reasonable care to ensure that the patient is aware of any material risks involved in any recommended treatment, and of any reasonable 
alternative or variant treatments"[6]. This places a duty upon surgeons to inform patients of the material risks, which for these purposes, are those which a reasonable patient in the same circumstance would attach significance to [6]. The intention of the court was to rebalance the scales in favour of a more patient-centric model to informed consent. However, patient testimony suggests that this did not transcend into practice when obtaining consent for mesh implantation [4]. In the aforementioned 2018 class action, the Court of Session heard four related cases brought by patients claiming to have suffered harm as the result of vaginal mesh implantation [24]. The claimants asserted that they had not adequately been informed of the risks listed on the Prolift IFU [24]. Those risks include the formation of adhesions, erosion caused by movement of the device and subsequent laceration of anatomical structures within the pelvic including nerves, blood vessels and pelvic organs [24]. Rather patients claimed only to have been advised of a "small risk of infection" which is common to most forms of surgery [24]. Considering the risks listed in the Proflit IFU raises the question of what patient would consent to that level of risk for a single surgery. The claimants also stated concerns that they were not informed of potentially life-changing longer-term risks, such as chronic pain, or the still undetermined risk implanted plastic may have upon fertility or pregnancy in women of reproductive age [24]. Many women, instead of being warned of the risks, were encouraged by reassurances that mesh implantation was the gold standard treatment; a quick solution for incontinence that was actually popular with other patients [4]. The court found that Ethicon had failed in its duty of care relating to the design and manufacture of the product and so the case and subsequent class action was settled for an undisclosed sum [24]. Yet as Campell et al 2018 attest, the scandal highlights ongoing deficiencies in informed consent which should be recognised and used to improve clinical practice [32]. Whilst the issues pertaining to the available evidence and conflict of interest have already been described, it is pertinent to take 
this opportunity to reflect upon issues specific to consent for device implantation, particularly disclosure of longer-term risks including foreseeable unknown risk [33].

The Proflift IFU described risks which my result during implantation of the device and gives recognition to complications such as inflammation, infection and scarring which can occur in the days and weeks after any surgical procedure [24]. However, the most common risk of mesh, that of erosion [14], often developed years after surgery was performed, creating a dormant period [4]. Whilst the IMMDR heard that some patients had been informed that perforation could occur during surgery there was little mention of this being a longer-term risk [4]. Whilst it may be argued that the patient consented to the known risk of perforation, it is important to differentiate between the modality of such perforation. A patient may, for example, anticipate that a surgical perforation could be immediately repaired, or addressed, during the surgery. However, perforation caused by mesh erosion is likely to create chronic pain and be extremely difficult to repair. The removal of mesh has been compared to "getting chewing gum out of hair"[7].

It is important, therefore, to recognise that information disclosure for consent to surgical device implantation should include two distinct categories of information. The first category should include information relating any risks, benefits and reasonable alternatives to the surgical procedure itself [12]. The second category should include information relating to the risks, benefits and reasonable alternatives to the implantable device. This will give recognition to the fact that a separate form of risk is linked to the implantable device itself. Such risk of harm was also evidenced in similar scandals involving metal-on-metal hip implants and PIP breast implants, both of which caused systemic toxicity in patients [3]. Information relating to the recommended device should include an explanation of the nature of the device, and any 
potential benefits relating to that product. The IMMDR heard that surgeons had not routinely shown patients device samples which could have supported shared decision-making by helping patients better understand the nature of the device and implantation procedure they are consenting to [4]. A crucial part of informed consent is ensuring patients understand what they are consenting to. Even if risks are unknown due to lack of long-term studies, patients must be made aware of this so that they can decide whether or not to incur such risk. Cockburn and Faye (2019) propose that disclosure of material risks for innovative treatment should include unknown or unforeseeable risks, conflict of interest and potentials for bias [33]. Whilst under UK law surgeons cannot be expected to warm of unforeseeable unknown risks [18], the authors argue that unknown harm is foreseeable in the case of innovative medical treatment [33]. Arguably unknown risk is foreseeable in the long-term when medical devices - which are essentially foreign bodies - are implanted into the body. Therefore, disclosure of unknown risks and conflict of interest can serve to reduce paternalism and simultaneously mitigate against bias. Whilst links with industry are important for device development, a surgeon's primary interest should be the patients. The GMC advises doctors to disclose such conflicts of interest with device manufacturers, however there is no corresponding legal duty [2]. Patients need to be aware of conflict of interest so that they themselves can determine whether a doctor's recommendations are subject to secondary influence. Arguably, conflict of interest disclosure should also be a key component of informed consent, allowing patients to evaluate whether information disclosed to them, particularly relating to risk and benefit, is likely to have been objectively evaluated by their surgeon.

\section{Conclusion}


It is important that in upholding patient-centric care, patients be more fully involved in shared, or supported, decision making. However, in the selection of reasonable treatments, a doctorcentric approach endures. The vaginal mesh scandal has revealed that a body of medical opinion can be influenced by conflict of interest or bias which can cloud judgements of what is truly in patients' best interests. Whilst it is unlikely that the courts will move away from the current Bolam standard, it is proposed that a greater recognition of patient-based evidence within evidence-based practice could provide a more patient-centric approach to determining the risks and efficacy of treatments. Furthermore, it is recommended that information disclosure for medical device implantation relate to any conflict of interest, the surgical procedure and the long-term implications of an implanted device. 


\section{References}

1. Department of Health. Liberating the NHS: No Decision about me without me Government response to the consultation. 2012, December 13 [cited 2021 February 8] United Kingdom Accessed. Gateway Reference 18444 Available at https://assets.publishing.service.gov.uk/government/uploads/system/uploads/attachme nt_data/file/216980/Liberating-the-NHS-No-decision-about-me-without-meGovernment-response.pdf

2. General Medical Council. Good Medical Practice. 2013, April 22. Updated 2020, November [cited 2021, February 8]. United Kingdom. Code: GMC/GMP/1120. ISBN: 978-0-901458-73-5. Available at https://www.gmc-uk.org/ethicalguidance/ethical-guidance-for-doctors/good-medical-practice

3. Heneghan C, Thompson M. Rethinking medical device regulation. J Roc Soc Med 2012; 105:186-8

4. Independent Medicines and Medical Devices Safety Review [Internet]. Cumberledge J, CBE. 2018, November 20. [Updated 2020, July 31; cited 2021, February 8]. Evidence. Available from https://www.immdsreview.org.uk/Evidence.html Particularly from 'Patient Groups-Pelvic Mesh' s.2.1.2, 3.1.8, 5.1.1, 5.1.2,6.1; Evidence of Properties of Mesh; Evidence from Clinicians, Academics and Other Individuals p15-31, Manufacturer Evidence: Ethicon.

5. Cumberlege J CBE. First Do No Harm - The Report of the Independent Medicines and Medical Devices Safety Review. 2020 July 8 [cited 2021 February 8] United Kingdom. ISBN 978-1-5272-6567-7. Available at https://www.immdsreview.org.uk/downloads/IMMDSReview_Web.pdf

6. Montgomery v Lanarkshire 2015 UKSC 11 available at https://www.supremecourt.uk/cases/uksc-2013-0136.html [cited 2021 February 8]

7. Directive 2007/47/EC of the European Parliament and of the Council of 5 September 2007 amending Council Directive 90/385/EEC available at https://eurlex.europa.eu/legal-content/EN/TXT/PDF/?uri=CELEX:32007L0047\&from=en [cited 2021 February 8]

8. Heneghan C. Updated EU medical Device Regulations: do they make a difference? 2018 November, 25 [cited 2021, February 8] In: BMJ EBM Spotlight [Internet] United Kingdom. Avilable at https://blogs.bmj.com/bmjebmspotlight/2018/11/25/carl-heneghan-why-eu-medicaldevice-regulations-are-a-smokescreen/

9. Regulation (EU) $2017 / 745$ of the European Parliament and of the Council of 5 April 2017 on medical devices, amending Directive 2001/83/EC. Available at https://eurlex.europa.eu/legal-content/EN/TXT/PDF/?uri=CELEX:32017R0745 
10. Bowers S. How lobbying blocked European safety checks for dangerous medical implants: Confidential injury and malfunction reports have tripled in less than 10 years in many countries [Internet] ICJI. 2018 Nov 25 [cited 2021 February 8] Available at https://www.icij.org/investigations/implant-files/how-lobbying-blockedeuropean-safety-checks-for-dangerous-medical-implants/

11. Busico V. Guilio Natta and the development of stereoselective propene polymerization. Adv Polym Sci. 2013; 257:37-8

12. Gornall J. The trial that launched millions of mesh implant procedures: did money compromise the outcome? BMJ 2018; 363:k4155

13. Emmett et al v Ethicon Women's Health \& Urology A. 2019 January 31, Case ID 130701495 in Koutouzos GD. Pennsylvania woman awarded \$41M pelvic mesh verdict. [Internet] 2019, February 1 [cited 2021 February 8] Wolters Kluwer. Available at https://lrus.wolterskluwer.com/news/products-liability-lawdaily/pennsylvania-woman-awarded-41m-pelvic-mesh-verdict-3/72205/

14. Swift SE. 'First do no harm' and the emerging story of the vaginal reconstructive mesh implant. IUJ 2007; 18; 983-984

15. Gornall J. Vaginal mesh implants: putting the relations between UK doctors and industry in plain sight. BMJ 2018; 363: k4164

16. Hurwtiz B. How does evidence based guidance influence determination of medical negligence? BMJ 2004; 329:1024

17. Sackett DL, Rosenberg WMC, Gray JAM, Haynes RB, Richardson WS. Evidence based medicine: what it is and what it isn't. BMJ 1996; 312(7023):71.

18. Duce v Worcester Acute Hospitals NHS Trust [2018] EWCA Civ 1307 2018, June 7. Available at https://www.bailii.org/ew/cases/EWCA/Civ/2018/1307.html

19. Bolam v Friern Hospital Management Committee [1957] 1 WLR 582 available at https://www.lexisnexis.com/uk/legal/results/enhdocview.do?docLinkInd=true\&ersKe $\mathrm{y}=23$ T134318055\&format $=$ GNBFULL\&startDocNo $=0 \&$ resultsUrlKey $=0 \quad \mathrm{~T} 134318$ $057 \&$ backKey $=20 \quad \mathrm{~T} 134318058 \& \mathrm{csi}=417192 \&$ doc $\mathrm{No}=1 \&$ scrollToPosition $=307$ [Cited 2021 February 8]

20. Samanta S, Mello MM, Foster C, Tingle J, Samanta J. The role of clinical guidelines in medical negligence litigation: A shift from the Bolam standard? Med L Rev 2006; 14(3): 321-366

21. Mulheron R. Trumping Bolam: A critical analysis of Bolitho's "gloss". Camb Law J 2010; 69(3): 609-638

22. Institute of Medicine (US) Committee on Conflict of Interest in Medical Research, Education, and Practice; Lo B, Field MJ, editors. Conflict of Interest in Medical Research, Education, and Practice. Washington (DC): National Academies Press 
(US); 2009 [cited 2021, February 8] 2, Principles for Identifying and Assessing Conflicts of Interest. Available from: https://www.ncbi.nlm.nih.gov/books/NBK22937

23. Hampton JR. Guidelines-for the obedience of fools and the guidance of wise men? Clin Med. 2003; 3: 279-84

24. AH v Greater Glasgow Health Board; and (second) Johnson \& Johnson Medical Limited and others [2018] CSOH 57 Available at https://www.scotcourts.gov.uk/docs/default-source/cos-general-docs/pdf-docs-foropinions/2018csoh57.pdf?sfvrsn=0

25. Sharma T, Choudhury M, Kaur B Naidoo B, Garner S, Littlejohns P, Staniszewska S. Evidence informed decision making: the use of "colloquial evidence" at NICE. Int J Technol Assess Health Care. 2015; 31(3):138-146.

26. Bradshaw A. Listening to the Patient's self-reported testimony: the authentic hermeneutical witness to the compassionate nurse? J Adv Nurs. 2013; 70(1): 60-67

27. Kennedy v Frankel [2019] EWHC 106 (QB) Available at https://www.bailii.org/ew/cases/EWHC/QB/2019/106.html [cited 2021, February 8]

28. Ford AA, Rogerson L, Cody JD, Ogah J. Mid-urethral Sling Operations for Stress Urinary Incontinence in Women. Cochrane Database Syst. Rev. 2015, Jul $1 ;(7): C D 006375$.

29. United States Food and Drug Administration (FDA). Urogynecologic Surgical Mesh: Update on the Safety and Effectiveness of Transvaginal Placement for Pelvic Organ Prolapse. July 2011 [cited 2021, February 8] Accessed at https://www.fda.gov/files/medical\%20devices/published/Urogynecologic-SurgicalMesh--Update-on-the-Safety-and-Effectiveness-of-Transvaginal-Placement-forPelvic-Organ-Prolapse-\%28July-2011\%29.pdf

30. Doyle C, Lennox L, Bell D. A systematic Review of the evidence on the links between patient experience and clinical safety and effectiveness. BMJ Open. 2013. 3:e001570

31. Brown K, Roseman D, Shaller D, Edgman-Levitan S. Measuring Patient Experience as a Strategy for Improving Primary Care. Health Aff: Millwood; 2010; 29(5): 921925

32. Campbell, P, Jha, S, Cutner, A. Vaginal mesh in prolapse surgery. Obstet. Gynecol. 2018; 20: 49-56.

33. Cockburn T, Fay M. Consent to Innovative Treatment. Law Innov Technol. 20193 Jan; 11(1): 34-54 